\title{
Space and Anthropology of Limit: A Philosophical Perspective
}

\begin{abstract}
Alberto Pirni *
CDG Lab, Sant'Anna School for Advanced Studies, Institute of Law, Politics and Development, Pisa, Italy
\end{abstract}

In no other living species does technology (or more precisely the need for technological development) play such an important role as it does in the human species. This rationale remains surely a matter of fact regarding the "traditional" or "common" condition of the man, understood as a being living "on the Earth" and with a specific and consolidated biological structure. However, any possible understanding of the same issue requires new efforts if and as far we try to maintain it open in a totally different context: "the space," namely, a not-specific place outside Earth in which the man is trying to give shape to a new path of its own surviving $(\S 1)$. Here rises what we would like to call the "anthropology of limit." In order to grasp a provisional content for such expression, we must proceed analytically, first, by reconsidering briefly the two conceptual sides implied in that expression, namely "What is a man?" and "What do we mean with limit?"

OPEN ACCESS

Edited by:

Debora Angeloni,

Scuola Superiore SantAnna, Italy

Reviewed by:

Vyacheslav Ivanovich Dokuchaev, Institute for Nuclear Research of the Russian Academy of Sciences, Russia Jean-Christophe Merle, University of Vechta, Germany

*Correspondence: Alberto Pirni a.pirni@sssup.it

Specialty section: This article was submitted to Cosmology,

a section of the journal Frontiers in Astronomy and Space

Sciences

Received: 16 March 2016

Accepted: 01 July 2016

Published: 08 August 2016

Citation:

Pirni A (2016) Space and Anthropology of Limit: A Philosophical

Perspective.

Front. Astron. Space Sci. 3:22. doi: 10.3389/fspas.2016.00022
(§ 2). Secondly, we should try to reconsider the twofold results under a synthetical or comprehensive point of view, trying to gather a common area of questioning that opens up if and as far we reconsider both conceptual sides of that expression within the "space-context" (§ 3).

Keywords: space, anthropology, limit, border, Darwin, Kant, autonomy, bioethics

\section{INTRODUCTION}

The human being is continually forced by his own nature to project himself beyond his limits. The debate on human nature-that is why man is the way he is, how he has been able to evolve, and who he can become in the near or more distant future-produces a stable set of questions that is constantly being posed anew, but to which the answers can never be exhausted. This is perhaps the outcome of an intrinsic specificity of human beings. As has been perceptively pointed out, in no other living species does technology (or more precisely the need for technological development) play as important a role as it does in the human species (Gerhardt, 2008). Almost every animal species is able to implement "techniques" in order to improve its living conditions, that is to produce tools or structures capable of enhancing its ability to procure food and defend itself. No animal, however, is as dependent on the constant renewal of its own capacities and their outcomes as the human being. This is also a fundamentally two-sided quality, rooted in two (opposing) emotional states: fear of inadequacy, on the one hand, anxiety for perfection, on the other.

As long as we refer to man in his natural state or "conventional" condition, namely as an earthly being with a specific biological structure, this peculiarity of the human being is a matter beyond dispute: to assert it is to make a factual statement. It immediately becomes a matter open to contestation, however, when we try to extend it to a new and very different context: space or the Universe, an unspecified expanse outside Earth where man is trying to carve out a new path for his own survival. 
This is where what we would like to call the anthropology of limit comes into play. To gain a preliminary understanding of what this expression means, we must proceed "analytically." The first step is to briefly remind ourselves of the two conceptual questions implied in the expression: "what is a human being?" and "what do we mean by limit?" ( $\$ 2)$. The next step is to reconsider these questions and the answers to them in a comprehensive or synthetic manner. We must try to establish a basis for further developing and turning these questions as we venture into the new cosmic context $(\$ 3)$.

\section{THE ANTHROPOLOGY OF LIMIT-I: ABOUT THE MEANING OF "HUMAN BEING" AND OF "LIMIT"}

Any serious attempt, however minimalistic, at formulating an answer to the question: what is a human being? would inevitably have to grapple with the questions at hand. To aid us in this quest, I would like to point out three fundamental features (and the nuances they entail) that have played a significant role in shaping the modern imaginary and mankind's own idea of what its role on Earth ought to be.

\section{Three Features (and Their Corresponding Nuances) of the Human Being as an Idea}

The first feature can be formulated based on an assumption made by Francis Bacon (1561-1626) at the very dawn of Western modernity: the human being was created to become "the master of the Earth."

This assumption is premised on two essential characteristics. The first of these is the peculiar relationship between Christianity and Humanism, specifically the awareness that human beings have been given a task by God. As long as he cannot access the heavenly delights that await him after life on Earth, man is obliged to improve his living conditions on Earth, using his rationality and inventiveness to enhance his own capacities. These two virtues of rationality and inventiveness - and here we come to the second Humanistic premise of that assumption-strive for the most extensive control of the world possible, a mastery of natural resources and of men ${ }^{2}$.

The two remaining features of the human idea would first manifest themselves in the work of Plessner and Gehlen, the originators of philosophical anthropology as an autonomous discipline.

Helmuth Plessner (1892-1985) paradigmatically defined the human being as an "eccentric being" (Plessner, 2003). While animals are "centered," being capable of a determined number of tasks that may vary in number from species to species, but will always remain "focused", defined and aprioristically predictable, man is simultaneously rooted in a context and located outside it, constitutively open to the broader world.

\footnotetext{
${ }^{1}$ The paradigmatic reference comes from his magnum opus, Novum Organon [1620]. For a classic English edition of this work see Bacon (1855). Bacon's work is now easily available in Bacon (2000).

${ }^{2}$ It is with this insight that Bacon's work establishes itself at the very core of modern concepts of "power."
}

Following Arnold Gehlen (1904-1976), in turn, we can establish as our third feature Gehlen's conception of man as "Mängelwesen" (deficient being; Gehlen, 1993). Once again this is based on a juxtaposition with the animal realm: while animals possess relationships with their environment that are fixed and genetically coded-as well as being subject to change through progressive processes of adaptation'-the human being appears to lack such a specific and codified environment. Thus, he is "deficient" in a positive sense, for he can adapt his agency to every possible context of life.

To sum up, the anthropological profile we have laid out defines an idea of the human being as master of the earth, but a master who is open and curious with regards to that which lies outside the self, constitutively deficient and incapable of permanently adapting to a single context of action.

\section{Limit vs. Border (Kant)}

This first trajectory invites us to shift our attention to a second level of analysis and, in particular, to a crucial terminological distinction, which constitutes my further conjecture. The distinction in question is that which Kant drew up between limits (Grenzen) and boundaries (Schranken) which, insofar as it is connected to the possibility of "pure" or "speculative" reason, can also be extended to the present question.

Right after the publication of his Critique of Pure Reason, Kant would also publish an additional work, the Prolegomena to Any Future Metaphysics That Will Be Able to Present Itself as a Science (1783), as a kind of accessible synthesis of the arguments contained in the Critique. In paragraph 57 ("Conclusion-On the determination of Limits of Pure Reason") of this work one encounters the following definition:

\footnotetext{
Limits [Grenzen] (in extended beings) always presuppose a space existing outside a certain definite place, and inclosing it; boundaries [Schranken] do not require this, but are mere negations, which affect a quantity, so far as it is not absolutely complete. But our reason, as it were, sees in its surroundings a space for the cognition of things in themselves, though it can never have definite notions of them, and is limited to phenomena only (Kant, 1997, p. 122).
}

According to Kant, therefore, whilst the limit "always presupposes a space," which is located outside it and the area which it encloses, the boundary simply negates this space and encloses a given territory from within without conceiving the possibility that something might exist beyond it. The limit defines its own area of legitimacy and, at the same time, looks beyond it in an attempt to understand what lies outside. Whilst aware of the otherness of what lies beyond, the limit is nonetheless always ready to go further and to engage in a discussion with the other with a view to enlarging itself. The boundary, by contrast, remains on the exact same territory, defining it more precisely and more conclusively. In other terms, if the concept of the limit-by its very nature-looks outward and beyond itself, that of the boundary does not cease to focus its gaze on itself or, rather, on its own interior, refusing to see anything other than 
that which it can master and, thus, demonstrating that either this does not exist or is irrelevant to its own existence.

To put it in Kantian terms, we must try to effect a transition from Schranke to Grenze, that is to turn the border into a limit, replacing an inability to manage complexity and an inability to innovate with a renewed energy for accomplishing both of these tasks.

In Kant's perspective, however, this distinction concerns only the theoretical or epistemological domain: in other words, it indicates the limit of so-called "scientific" knowledge, the type of knowledge which is legitimated within the transcendental turn developed by Kant's Critique of Pure Reason.

One of the most common usages of the term "border"-or of its counterpart "limit" - is associated with the political sphere. Here it is used to demarcate precise boundaries for the legitimacy of a specific political order, or the validity of a certain system of juridical norms which regulates coexistence among individuals. In the field of political philosophy this is what we call the "territorialization of politics."

For some decades this concept has been fundamentally put into question by the complex range of processes grouped under the term "globalization." And the development of this issue at the global level is one of the most promising avenues for the contemporary debate regarding such a term, that embraces the entire sweep of the social sciences from philosophy to law, from cultural studies to economics, sociology, history, and psychology.

Nonetheless, the human being's drive to surpass his own limits manifests itself at this level as well. Following the establishment of a new, unstable balance of powers after the Second World War, man's effort to conquer "territory" beyond the Planet Earth has been continually stimulated with the ever increasing investment of economic resources. Only with the global crisis starting in 2007 did this investment arguably begin to plateau.

If the quest to conquer spaces beyond the borders of our planet generates a need for a concomitant expansion of the discourse surrounding borders and limits, then we should also acknowledge the need for an expansion of the disciplinary perspectives involved in our conceptualization of the subject. By acknowledging this, perhaps we could also recognize that we are on the verge of provoking a meltdown of traditional disciplinary boundaries. Thus, we are currently awakening to the possibility of a new and more comprehensive approach that follows in Kant's footsteps, by trying to convert borders into limits and to transform disciplinary borders into possibilities of effective dialogue among scientists from different disciplines who are nevertheless equally committed to a topic that lies at the frontier of human comprehension.

\section{TOWARD AN ANTHROPOLOGY OF LIMITS-II: BIOETHICAL CHALLENGES}

The awareness of this precarious location at the precipice of the scientific unknown, in other words, a research problem whose knowability depends on the acquisition of methods and tools that the scientist does not yet possess, is made evident from the completely different focus of any possible analysis in this field. In other words, the task of converting borders into limits confronts us simultaneously with the problem of a political frontier and with the problem of having to navigate an intersection between two separate biological-and, I would add, ontological_realms that cannot be welded together.

Thus, we are approaching a frontier beyond which the disciplinary lenses that have historically been used to tackle the fundamental aspects of "human nature," namely biology and ontology, would have to be revolutionized if they are to remain of any use.

Any further developments in a possible anthropology of limit should start from this basic recognition: that we stand before a border that perhaps cannot be converted into a limit.

The abundance of scientific evidence for this proposition is nothing new. To return to our initial assumption, any future anthropology of limit ought to sketch out the outlines of several open questions or of some fundamental challenges that (1) do not neglect the initial assumption; (2) seriously consider the need for an enlargement and fusion of disciplinary approaches; (3) do not underestimate the novel implications of the word "mastery" when used to denote that which technological development has rendered either real or possible.

In this context, we would like to draft at least two of a potentially unfinished list of challenges regarding this area of research: both belong to the context of bioethics.

\section{Two Bioethical Challenges}

The comprehensive bioethical challenge we would like to address in this framework appears two-fold. We would like to convey its general characteristics and to describe it by raising two different, but ultimately related questions.

\section{A Border or a Limit for Human Autonomy?}

We started with the image of man as master of the Earth who, to follow Bacon's suggestion, seeks at all costs to enlarge and deepen his sphere of mastery. If we consider expanding this image further, we will be confronted by a new question. Man was and remains the conqueror of the Earth thanks to his capacity for "autonomy." It is a conventional wisdom that the specific factors that distinguishes man from other beings of comparable biological complexity is precisely such a capacity.

In its most basic sense, the adjective "autonomous" refers to the individual subject's ability to become the starting point (cause) of a series of physical effects. In a more comprehensive sense, "to be autonomous" means to be capable of elaborating and thus pursuing a certain conduct or a series of actions that constitute a behavior.

Typically, however, we recognize that any attempt at expressing individual autonomy "on Earth" has to come against several "obstacles" and to rest upon a certain set of data and conditions. But, at the same time, we can always predicate that "it is up to me," namely that it is a matter of individual choice whether one does or does not perform a specific action or pursue a specific goal.

As soon as we shift the entire range of questions about choice, decision-making and autonomy that we have so crudely simplified outside its "traditional" realm of discussion, namely 
that of life on Earth, we run up against a distinct need for re-semantization.

It is a conventional wisdom that any human movement outside the terrestrial atmosphere relies to a tremendous extent on technology and on technological devices. We should, in fact, admit that practically no decision concerning space exploration could be taken without the support offered by technology. We might even be forced to think that every such decision is dependent on obstacles, data, and conditions that only technological means can take into account and that can only be elaborated and organized into an adequate line of conduct through recourse to technology. In short, once we move beyond Earth, we find ourselves in an environment that excludes the possibility of human autonomy altogether.

Therefore, in very concise terms, we should raise the question here as to whether the borders of the Earth correspond to the boundaries within which the concept of "human autonomy" can be sensibly applied. Is it possible in this case to turn this border into a limit?

A complete anthropology of limit should develop all possible expressions of these questions in order to explore new ways of basing autonomy upon an area of agency that seems to exclude it altogether-at least in terms of the categories through which we conceptualize it.

We began with a discussion of man's capacity for exercising a sort of exclusive mastery over two different realms: "the earth," understood as territory external to the individual subject, and "the self" by focusing on the capability of organizing biological stimuli and individual purposes into a line of autonomous conduct.

By transgressing the earth's borders, we can finally begin to perceive that, from a situation of complete mastery over the world and over ourselves, we have passed into a state where technology is the master of us and of our decisions.

Here we must face our first bio-ethical challenge. We must recognize that turning borders into limits with regard to autonomy, that is the biological distinction between human beings and all other beings on Earth, might fail and, at any rate, that it ought to take the need for a deep re-semantization of the term "autonomy" into consideration.

To put things even more explicitly, we have arrived at a border beyond which we can no longer uphold a central tenet of natural and social sciences to date: namely the hitherto incontestable truth that "man is an autonomous agent."

At this point we can put forward a preliminary conclusion. If we can no longer legitimately predicate the autonomy of the human being, then we also lose the ability to affirm one of the fundamental characteristics that distinguish such a being from other Earthly creatures from a biological, neurological and philosophical point of view.

\section{Toward New Borders and Limits for Human Physiology?}

This last point helps us to approach the second bioethical challenge at hand. In order to progress in our understanding of such a limit, we have to make a step back and reconsider Charles Darwin's work of 1844, The Foundation of the Origins of Species.
This long essay anticipated Darwin's magnum opus, On the Origin of Species, which the author only decided to publish in 1859 . Toward the end of the essay, Darwin includes a rather strange chapter, entitled "Abortive or Rudimentary Organs" (Darwin, 1909).

Darwin approaches the topic from both physiological and naturalistic perspectives. He does not assign a specific meaning to the words "abortive" and "rudimentary" or make any strong distinction between them, instead imputing to them a general connotation of underdevelopment.

Parts of structure are said to be "abortive" or, when in a still lower state of development, "rudimentary."

In addition, he presents several example of such abortive or rudimentary organs:

Thus, the rhinoceros, the whale, etc., have, when young, small but properly formed teeth, which never protrude from the jaws; certain bones, and even the entire extremities are represented by mere little cylinders or points of bone, often soldered to other bones: many beetles have exceedingly minute but regularly formed wings lying under their wing-cases, which latter are united never to be opened (Darwin, 1909, p. 231).

This is not the place for a more comprehensive examination of such specific instances. For our purposes it is sufficient to point out that most naturalists recognize-at least in the vast majority of such cases-that these organs do not have any evident use or function for the organisms in question: they are "absolutely useless." In Darwin's view physiologists ascribed a slightly different meaning to the word "abortive":

Physiologists and medical men apply the term "abortive" in a somewhat different sense from naturalists; and their application is probably the primary one; namely, to parts, which from accident or disease before birth are not developed or do not grow: thus, when a young animal is born with a little stump in the place of a finger or of the whole extremity, or with a little button instead of a head, or with a mere bead of bony marker instead of a tooth, or with a stump instead of a rail, these parts are said to be aborted (Darwin, 1909, p. 234).

Physiologists thus considered there to be a specific cause in the form of an extraordinary occurrence that could explain the presence of abortive organs. Naturalists, by contrast, posited that even in such extraordinary cases (e.g., of disease) the "abortive results" would be hereditarily transmitted to the next generation. Darwin, however, sought to rework both of these assumptions so that they would be in conformity with his theory ${ }^{4}$. The most important point for our discussion only emerges in the final paragraph of this fascinating chapter:

There seems to be some probability that continued disuse of any part or organ, and the selection of individuals with such parts

${ }^{3}$ Darwin (1909, p. 231). It should also be emphasized that Darwin fails to provide such a distinction in On the Origin of Species, even though the same topic is covered in Chapter 14 (See Darwin, 1962, pp. 414-457, spec. pp. 450-457).

4 "The strong hereditary tendency to reproduce every either congenital or slowly acquired structure, whether useful or injurious to the individual, has been shown in the first part <of the work>" (Darwin, 1909, p. 234). 
slightly less developed, would in the course of ages produce in organic beings under domesticity races with such parts abortive. We have every reason to believe that every part and organ in an individual becomes fully developed only with exercise of its functions; that it becomes developed in a somewhat lesser degree with less exercise; and if forcibly precluded from all action, such part will often become atrophied (Darwin, 1909, pp. 235-236).

As we know, Darwin was referring here exclusively to animals and plants. Nonetheless, as we "transgress" the Earth's borders, perhaps we should consider whether the same processes might not be extended to humankind.

Thus, the question arises: are we able to categorically exclude the possibility of such a process in the case of humans should "the conquest of the space" be taken further? At present this only applies to astronauts, but by extension what would happen to future generations of humans if in a futuristic scenario such trips became more common and more accessible?

Humans are biologically and physiologically adapted to life on Earth. By way of example, we could point out that humans are "programmed" to make direct "contact" with the world outside their bodies, to have tactile experiences starting from the first moments of their lives, starting from their first encounter with their mothers or with the subjects who nourish them. The tactile experience, therefore, becomes one of the most basic and essential perceptual mediums for man. We could go further and state that the answer to the question "what is man?" partially depends on the modality of his tactile contact with the external world and the way this world becomes his or hers as a result of the repeated nature of this experience.

If we accept this premise, then we have to ask an additional ethical question: are we fully aware of and capable of accepting the possibility that humans with abortive or rudimentary organs may be born in the future?

Though in the example given we focused on touch, we could use the same analogy to deal with other human capacities: sight,

\section{REFERENCES}

Bacon, F. (1855). The Novum Organon, or A True Guide to the Interpretation of Nature (Transl. by G. W. Kitchin). Oxford: Oxford University Press.

Bacon, F. (2000). The New Organon, eds L. Jardine and M. Silverthorne. Cambridge: Cambridge University Press.

Darwin, C. (1909). "The foundations of the origin of species," in Two Essays Written in 1842 and 1844, eds C. Darwin and F. Darwin (Cambridge: Cambridge University Press), 57-255.

Darwin, C. (1962). On the Origin of Species by Means of Natural Selection or the Preservation of Favoured Races in the Struggle for Life [1859] (edited by G. Gaylord Simpson). New York, NY; London: Collier-Mac Millan.

Gehlen, A. (1993). Der Mensch. Seine Natur und Seine Stellung in der Welt [1940], in Id., Gesamtausgabe, Hrsg, Vol. 1, ed K.-S. Rehberg (Frankfurt: Klostermann).

Gerhardt, V. (2008). "Homo publicus," in Was ist der Mensch? ed D. Ganten, V. Gerhardt, J.-Ch. Heilinger, and J. Nida-Rümelin (Berlin/New York, NY: de Gruyter), 97-102.

Kant, I. (1997). Prolegomena zu Einer Jeden künftigen Metaphysik, die als Wissenschaft Wird Auftreten Können [1783]/Prolegomena to Any Future eating, and digesting food, walking, or to speak in terms of "organs," the eyes, the stomach, legs or more generally, the entire muscular system.

Here the attempt to convert a biological border into a biophysiological limit-that opens the door to an atrophying of our organs and of parts of our body, but perhaps also to an atrophying of certain parts of the human brain-should be carefully taken into consideration.

It is by addressing this question and attempting to articulate this second bio-ethical challenge that an anthropology of limit establishes its role and its claim to disciplinary legitimacy.

To conclude, we can affirm that the anxiety for perfection from which we started, if linked to the dialectics between limits and borders from which an anthropology of limit originates, and if applied to an extra-terrestrial context, gives rise to a host of unexplored issues and fundamental challenges that are far from being fully known and far from being solved. Possible solutions, or, at least, superior conceptualizations of these challenges can be arrived at only if we agree to open up the frontiers of our disciplines, to convert our borders into limits and, in so doing, to inaugurate a new wave of interdisciplinary and global responsibility toward humankind. Through a re-semantization of key concepts, it is this duty that we must prioritize above everything else.

\section{AUTHOR CONTRIBUTIONS}

The author confirms being the sole contributor of this work and approved it for publication.

\section{FUNDING}

The elaboration and publication of this essay has been possible thanks to a contribution received from Sant'Anna School for Advanced Studies (Pisa)-PhD School in Life Sciences.

Metaphysics that Will be Able to Come Forward as Science (edited by G. Hatfield). Cambridge: Cambridge University Press.

Plessner, H. (2003). Die Stufen des Organischen und der Mensch. Einleitung in die Philosophische Anthropologie [1928], in Id. Gesammelte Schriften, Hrsg., Vol. 4, ed V. G. Dux (Darmstadt: Wissenschaftliche Buchgesellschaft).

Conflict of Interest Statement: The author declares that the research was conducted in the absence of any commercial or financial relationships that could be construed as a potential conflict of interest.

The handling Editor declared a shared affiliation, though no other collaboration, with the author AP and states that the process nevertheless met the standards of a fair and objective review.

Copyright (c) 2016 Pirni. This is an open-access article distributed under the terms of the Creative Commons Attribution License (CC BY). The use, distribution or reproduction in other forums is permitted, provided the original author(s) or licensor are credited and that the original publication in this journal is cited, in accordance with accepted academic practice. No use, distribution or reproduction is permitted which does not comply with these terms. 